\title{
Exploring Myths: Cyberbullying of College Faculty
}

\author{
Janet M. Joiner, PhD, LMSW \\ University of Detroit Mercy \\ Department of Social Work \\ United States of America
}

\begin{abstract}
Anonymous online rating sites provide outlets for students and others to share their experiences related to professors, courses, and colleges and universities. College faculty are often the focal point of anonymous feedback and could become targets for sometimes unfair online ratings. This paper explored the extent to which faculty perceived cyberbullying of faculty to be an issue on anonymous rating sites, faculty observations about the accuracy of information posted to anonymous websites about themselves, and the extent to which faculty discuss with students their expectations regarding appropriate use of the Internet, social media, and mobile technologies. Further research is needed to explore the influence of public anonymous ratings on faculty course enrollments and faculty overall job satisfaction.
\end{abstract}

Keywords: Cyberbullying, Ratemyprofessors.com, faculty, social work, mental health

\section{Introduction}

Innovative technology tools, increases in the availability of online communication outlets, and the anonymity of the Internet provide a venue for people to review, evaluate, and assess products, services, and individuals (Perna, 2016). In contemporary society, individuals can visit social media and rating sites, like Yelp, Better Business Bureau, and TripAdvisor, to provide public, anonymous valuations of their experiences related to restaurants, retail outlets, and service providers. For example, individuals seeking information about specific physicians or other healthcare professionals can visit websites, including Healthgrades.com, RateMDs.com, and Vitals.com to review experiences and recommendations of others. Providing anonymous online comments and ratings can provide consumers with valuable feedback, although some negative feedback could be viewed as cyberbullying (Hossain, 2010).

Contemporary students can use anonymous sites to rate and post comments about faculty, courses, and colleges and universities. Brown and Kosovich (2015) argued that college faculty often is the focal point of this feedback, with some students using anonymous rating sites (ARS; e.g., Ratemyprofessors.com [RMP], Rateaprof.com, RatingsOnline.com, PassCollege.com, Pickaprof.com, Professorperformance.com, Studentdude.com) to shop for a professor. RMP, the ARS that launched in 1999 has become one of the most popular anonymous sites for evaluating college faculty (Bleske-Rechek \& Fritsch, 2011).

According to its website (http://www.ratemyprofessors.com/About.jsp, n.d.), RMP houses the most extensive collection of professor ratings, totaling more than 19 million postings discussing 1.7 million professors in more than 7,500 educational institutions. Reid (2010) indicated that students depend on ARS that allow raw, oftentimes uncensored assessments of faculty teaching styles to help them make informed decisions about potential courses and faculty. Hayes and Prus (2014) found that "students perceive RMP among the most reliable and useful sources for making course selection decisions, rating it to be just as useful and reliable as their friends, other students, their academic advisor, and the university catalog" (p. 684).

Social learning theory by Bandura (1977) is the theoretical framework for the current study. Social learning theory proposed that individuals learn from observing and interacting with others in their world. According to Hill, Song, and West (2009), "characteristic of social learning theory is that of modeling. A model is a pattern or example that is provided to a student to illustrate how one might behave" (p. 91). Students can mirror the behavior of others, form opinions, and post ratings about faculty on RMP. Researchers (Watts, Wagner, Velasquez, \& Behrens, 2017) theorized the anonymity of ARS could inspire some students to post comparable comments about faculty that might not otherwise be shared in face-to-face conversations. 
Miller and Morris (2016) conducted a study using social learning theory as a foundation for examining offending behaviors of college students engaged in traditional face-to-face peer groups versus those in fully online virtual peer groups. Findings indicated that students viewed their peer groups favorably; with virtual peers exerting more influence on offending behaviors of individual group members. According to Miller and Morris (2016), comments posted on ARS could be based on opinions of other site participants instead of original experiences. Faculty could feel that some negative comments that were not based in fact could be considered cyberbullying. Cassidy, Faucher, and Jackson (2017) reported a lack of published research that examined experiences of faculty members who had been cyberbullied. Some faculty suggested that ARS postings damaged their standing in the academic community and negatively influenced course enrollments (Minor, Smith, \& Brashen, 2013). Investigating the extent to which faculty perceived cyberbullying was an issue on ARS was the focus of the present study.

\section{Literature Review}

Research related to student use of ARS to evaluate professors is emerging, with attention focusing on cyberbullying of college faculty. Cyberbullying is described as the use of information and communication technologies (ICTs; e.g., laptops, tablet devices, cell phones, video and/or audio ink pens) to access ARS and share information about a person (Bauman \& Bellmore, 2015). This information could be perceived as harassing, intimidating, or embarrassing by the professor being rated.

A research study by Blizard (2016) sent links to an online survey on cyberbullying to 1,040 faculty. Thirty-six faculty who had experienced cyberbullying participated in the study. Although the response rate was low, findings indicated cyberbullying resulted in negative feelings, including a loss of desire to go to work (68\%), interest in quitting their job $(53 \%)$, thoughts of retaliation $(21 \%)$, and thoughts of self-harm $(5 \%)$. The author argued that "cyberbullying of faculty by students constitutes a form of workplace violence" (p. 109).

Eskey and Roehrich (2015) conducted a study with 550 online faculty on their perceptions of institutional support for cyberbullied faculty. Using responses from 202 of these faculty, the researchers found that $50 \%$ of respondents had experienced student cyberbullying, with $37 \%$ of these faculty indicating they had been cyberbullied multiple times. However, $39 \%$ of the participants did not feel cyberbullying was a major problem and $38 \%$ considered it a minor problem. Among those who had been cyberbullied, $21 \%$ indicated their problem had not been managed well by the university administrators.

Cassidy et al. (2014) received responses from 121 faculty who completed an online survey on cyberbullying. Study findings indicated that $12 \%$ had been cyberbullied by a student, and $9 \%$ by a faculty colleague. Further results revealed that messages posted online about female faculty "affected their ability to work, their mental health and their relationships outside the university, with one-third wanting to quit" (p. 294). Minor et al. (2013) conducted a similar study related to cyberbullying with 346 faculty at a large online university. Sixty-eight (20\%) of the faculty responded, with $42(61.8 \%)$ reporting they had not been cyberbullied by students. Faculty who reported being cyberbullied had concerns related to obtaining future teaching assignments.

Kornell and Hausman (2016) argued that creating challenging course content designed to strengthen student academic knowledge and skills is the intended goal of instruction, the result can provide a path to potential cyberbullying, poor student evaluation of teaching (SET) ratings and equally poor ARS scores. Brown and Kosovich (2015) provided compelling evidence that students could be influenced by faculty ARS scores. They reported that professors with positive comments and equally strong ARS scores have courses that fill more quickly. Additionally, "students treat the course selection process as consumers selecting products. They pick course sections based upon the various attributes of instructors" (p. 507). Researchers (Bleske-Rechek \& Fritsch, 2011; Hayes \& Prus, 2014) indicated that student consensus about instructor quality was consistent whether the instructor was considered high or low quality.

Each study included in this section provided information on the percentage of professors who had been cyberbullied in postsecondary institutions. The percentages of professors indicating they had been cyberbullied varied in each study. An extensive search of the Internet provided no additional information regarding a general percentage of professors who had been cyberbullied in ARS postings. Technological advances, including ARS, have ushered in course-related issues and unique possibilities for student engagement. Faculty and students use ICTs to exchange ideas and engage with course content. Students can use ICTs to conduct relevant research and complete assignments. 
However, some students use ICTs during lectures for nonacademic purposes that interfere with their ability to concentrate (Faucher, Jackson, \& Cassidy, 2015). Some faculty use ICTs, such as social media, with students to raise awareness of certain social problems. However, use of these digital tools with students present both challenges and opportunities (Minor, Smith, \& Brashen, 2013; Roblyer, McDaniel, Webb, Herman, \& Witty, 2010).

Many faculty continue to have expectations of a level of classroom privacy and confidentiality, even in the digital age. The exchange of diverse perspectives among faculty and students is a key component of learning. When these discussions are captured electronically and shared in online venues without the benefit of context, background of the discussion, or the faculty member's knowledge; the free exchange of ideas could be hindered. These online posts, if viewed out of context, could place faculty at risk for reputational damage, and in some cases affect future employment opportunities (Daniloff, 2009). Another challenge with the use of ICTs is livebroad casting sidebar conversations between students and faculty on social media without the professor's knowledge or consent. Live-streaming these conversations could result in embarrassment, loss of dignity, as well as emotional and social isolation that could affect faculty mental health and overall psychological well-being (Kolowich \& Quintana, 2017).

Although research findings (Blizard, 2016; Eskey \& Roehrich, 2015) indicated that the number of college faculty reporting cyberbullying is small, it could be argued that cyberbullying of college faculty is not a myth. Forbes Magazine used data from an ARS to rank U.S. colleges and universities (Bleske-Rechek \& Michels, 2010). The use of these ARS data might suggest the extent to which ARS could influence decisions about the quality of higher education institutions. Multiple research studies have reported high numbers of faculty indicating they have not been cyberbullied (Blizard, 2016; Cassidy et al. 2014). However, no research was found that focused on benefits that faculty could attain from their strong ARS scores and positive online comments. Similarly, advantages that colleges and university could enjoy from having "rock-star" faculty who receive high ARS scores and positive comments are unknown.

\subsection{Placing ARS Scores in Context}

Otto, Sanford, and Douglas (2008) indicated that anonymous ratings could be posted by anyone. These online ratings may be subjective, influenced by emotion rather than impartiality. The targeted individual and/or group may experience lasting effects.

Many institutions offer faculty instructional design services to enhance teaching and raise awareness about emergent ICTs in the classroom. However, little emphasis has been placed on educating faculty about monitoring their digital reputations and addressing student use of ARS. Cassidy et al. (2014) indicated that some faculty might consider lowering academic expectations or artificially inflating grades to motivate students to provide positive feedback on ARS.

Miranda (2018) used an ARS as a teaching tool, with the goal to decrease the number of low ratings and undesirable comments received from students. To achieve this goal, he offered students an opportunity to improve their performance by retaking a course quiz. The scores on their second quiz replaced students' original quiz score, even if the repeated score was lower. Of the 35 students enrolled in the course, 21opted to repeat the quiz. Results indicated that 18 students improved their quiz scores, two students' scores remained the same, and one student obtained a lower score. The instructor indicated that providing students with decision-making authority to repeat a quiz was directly linked to how they viewed themselves as learners and him as the course instructor. By offering students an opportunity to improve their academic performance, their levels of satisfaction with the course and the instructor could increase, resulting in fewer low ARS scores and unfavorable comments.

The influence of ARS posts on faculty mental health is not well known. However, faculty targeted for low ARS scores and poor feedback could experience mental health challenges similar to those reported by individuals who had been cyberbullied in secondary educational settings (Cassidy, Faucher, \& Jackson, 2017). These mental health challenges can include anxiety, depression, insomnia, psychosomatic issues, dissociation, etc. (Watts et al., 2017).

Faculty who have been cyberbullied could be apprehensive about discussing their experiences with academic leadership (Minor et al. 2013). Mental health issues could be exacerbated with repeated visits to ARS, resulting in increased anxiety or feeling victimized, similar to post-traumatic stress disorder (Blizard, 2016). Some faculty worried that they could be denied future teaching contracts if they reported the abuse (Eskey \& Roehrich, 2015). 
These research findings underscored the importance of committing institutional funding to support cyberbully prevention programs, including conflict management programs for faculty, staff, and students (Zalaquett \& Chatters, 2014). Miranda (2018) argued that some faculty regularly visit ARS to view their scores and post feedback; however, they rarely acknowledge this behavior.

The purpose of the current study was to investigate the extent to which faculty perceived cyberbullying of faculty as an issue on ARS, including their observations about the accuracy of information posted to these sites; perceptions about changing student behaviors based on the proliferation of mobile devices, social media, and the Internet; and the extent to which responsible use of the ICTs was discussed with their students.

The following research questions were addressed in this study:

1. To what extent is student cyberbullying of faculty widespread on RMP?

2. To what extent is faculty cyberbullying of other faculty widespread on RMP?

3. How likely are faculty to change their teaching styles to avoid negative ratings from students on RMP?

4. To what extent are faculty expectations regarding appropriate use of the Internet, social media, and mobile technologies discussed with students?

\section{Method}

Prior to conducting the study, the researcher received approval for the study design, sampling procedure, and data collection for human subjects from the Institutional Review Board at the University. The current survey was developed using SurveyMonkey.com.

\subsection{Participants}

Potential participants for this study were full and part-time faculty in colleges and universities. A link to the survey was included in an email sent to all faculty members of a private urban university. In addition, announcements with the link to Survey Monkey were posted on social media. Because links were posted on social media, the number of different institutions represented in the sample is unknown. Results for the current study are based on 28 participants. The majority of participants identified as Caucasian $(n=22,78.6 \%)$, with $6(21.4 \%)$ men participating in the study. Participants ranged in age from under 35 to over 65, with the largest group reporting their ages between 45 and $54(n=9,32.1 \%$; See Table 1).

Table 1: Demographic Characteristics $(\mathbf{N}=28)$

\begin{tabular}{lll}
\hline Demographic Characteristics & $\mathrm{N}$ & $\%$ \\
\hline Gender & & \\
$\quad$ Female & 22 & 78.6 \\
$\quad$ Male & 6 & 21.4 \\
Age & & \\
$\quad 25$ to 44 & 9 & 32.1 \\
45 to 54 & 9 & 32.1 \\
54 to 64 & 8 & 28.7 \\
65 and older & 2 & 7.1 \\
Ethnicity & & \\
$\quad$ Asian/Pacific Islander & 1 & 3.6 \\
$\quad$ African American & 4 & 14.2 \\
$\quad$ Hispanic & 1 & 3.6 \\
Caucasian & 22 & 78.6 \\
\hline
\end{tabular}

Fifteen (53.6\%) respondents indicated they taught social work. Other programs included nursing, sciences, psychology, and liberal arts. Respondents reported their ranks as full professor $(n=4,14.3 \%)$, associate professor $(n=10,35.7 \%)$, assistant professor $(n=9,32.1 \%)$, and adjunct $(n=5,17.9 \%)$. Most respondents were either tenured $(\mathrm{n}=13,46.4 \%)$ or tenure track $(\mathrm{n}=6,21.4 \%)$, with $9(32.2 \%)$ participants adjunct or clinical. Many participants taught face-to-face courses $(\mathrm{n}=14,50.0 \%), 4(14.3 \%)$ indicated they taught online only, and 9 $(32.1 \%)$ taught courses that were either online or face-to-face. One $(3.6 \%)$ participant indicated he/she taught hybrid courses (See Table 2.) 
Table 2: Faculty Characteristics

\begin{tabular}{|c|c|c|}
\hline Faculty Characteristics & $\mathrm{N}$ & $\%$ \\
\hline \multicolumn{3}{|l|}{ Faculty Status } \\
\hline Adjunct Professor/Instructor & 5 & 17.9 \\
\hline Assistant Professor & 9 & 32.1 \\
\hline Associate Professor & 10 & 35.7 \\
\hline Full Professor & 4 & 14.3 \\
\hline \multicolumn{3}{|l|}{ Faculty Rank } \\
\hline Adjunct & 4 & 14.3 \\
\hline Clinical (Nontenured track) & 5 & 17.9 \\
\hline Tenure Track & 6 & 21.4 \\
\hline Tenured & 13 & 46.4 \\
\hline \multicolumn{3}{|l|}{ Student Type } \\
\hline Undergraduate & 15 & 53.6 \\
\hline Graduate & 8 & 28.5 \\
\hline Both undergraduate and graduate & 5 & 17.9 \\
\hline \multicolumn{3}{|l|}{ Teaching Area } \\
\hline Social work & 15 & 53.6 \\
\hline Nursing & 1 & 3.6 \\
\hline Sciences (Biology, Chemistry, & 1 & 3.6 \\
\hline Physics, etc.) & 2 & 7.1 \\
\hline Psychology & 9 & 32.1 \\
\hline Liberal arts & & \\
\hline \multicolumn{3}{|l|}{ Course Delivery Method } \\
\hline Fully online courses & 4 & 14.3 \\
\hline $\begin{array}{l}\text { Traditional courses (onsite, face-to- } \\
\text { face) }\end{array}$ & 14 & 50.0 \\
\hline Both online and traditional courses & 9 & 32.1 \\
\hline $\begin{array}{l}\text { Hybrid courses (classes meet } \\
\text { partially online and onsite) }\end{array}$ & 1 & 3.6 \\
\hline
\end{tabular}

\subsection{Instrument}

A survey was developed by the researcher to measure perceptions of cyberbullying by faculty at postsecondary institutions. The survey was based on literature on cyberbullying that has been published in referred journal articles. Thirty-one items were included on the survey that used a combination of response formats. Some items, such as faculty and demographic characteristics used a forced-choice format, with other items regarding perceptions of cyberbullying using Likert-scaled formats to measure faculty perceptions of cyberbullying and its effects on college campuses. The survey also included short answer responses to questions regarding faculty reflections on cyberbullying and if they discussed their concerns with students.

\section{Findings}

Participants indicated their perceptions regarding student postings on ARS. When asked if they had been cyberbullied based on their role as faculty, the majority indicated no $(n=24,85.7 \%)$, providing support that cyberbullying of college faculty was not widespread. Nine $(32.1 \%)$ respondents indicated they were not concerned about being cyberbullied on ARS.

Responses related to faculty views that cyber bullying was widespread were mixed, with6 (21.4\%) indicating not at all widespread and12 (42.9\%) participants believing that faculty cyberbullying of other faculty was not widespread. Twenty-three (82.1\%) reported they had visited ARS to see if they had been evaluated. 
Thirteen (46.4\%) thought ARS posts were accurate, with 8 (28.6\%) participants reporting online posts related to them were not at all accurate. Seven $(25.0 \%)$ indicated that they could not speak to the accuracy of the posts because they had not appeared on any of the ARS that allowed faculty ratings.

Faculty $(\mathrm{n}=17,60.7 \%)$ were unlikely to change their teaching style to avoid negative online ratings from students; however, 1 (3.6\%) faculty indicated that he/she would be very likely to change their teaching style. Seven $(25.0 \%)$ respondents indicated that poor ratings found on anonymous faculty rating sites would be used to determine if an adjunct faculty member would be hired and/or retained by an institution. In contrast, 5 (17.9\%) participants indicated hiring and retention issues were not affected by poor ratings on ARS.

Faculty were asked how satisfied they were with the way their institution handles faculty cyberbullying. Nineteen (67.9\%) faculty reported they were neither satisfied nor dissatisfied with how their university handled faculty cyberbullying. Four $(14.3 \%)$ faculty indicated they had experienced cyberbullying and $5(18 \%)$ believe their teaching career has been adversely impacted by online rating sites. (See Table 3.)

Table 3: Perceptions of Anonymous Ratings $(\mathrm{N}=28)$

\begin{tabular}{|c|c|c|}
\hline Perceptions of Anonymous Ratings & $\mathrm{N}$ & $\%$ \\
\hline $\begin{array}{l}\text { Concern about being cyberbullied on anonymous sites to rate faculty } \\
\text { Very concerned/Concerned/Somewhat concerned } \\
\text { Not at all concerned }\end{array}$ & $\begin{array}{l}19 \\
9\end{array}$ & $\begin{array}{l}67.9 \\
32.1\end{array}$ \\
\hline $\begin{array}{l}\text { Accuracy of posts related to participants on rating sites } \\
\text { Very accurate/Accurate/Somewhat accurate } \\
\text { Not at all accurate } \\
\text { I do not appear on an anonymous site that allows faculty ratings }\end{array}$ & $\begin{array}{l}13 \\
8 \\
7\end{array}$ & $\begin{array}{l}46.4 \\
28.6 \\
25.0\end{array}$ \\
\hline $\begin{array}{l}\text { Student cyberbullying of faculty } \\
\text { Very widespread/Widespread/Somewhat widespread } \\
\text { Not at all widespread }\end{array}$ & $\begin{array}{l}22 \\
6\end{array}$ & $\begin{array}{l}78.6 \\
21.4\end{array}$ \\
\hline $\begin{array}{l}\text { Faculty cyberbullying of other faculty } \\
\text { Very widespread/Widespread/Somewhat widespread } \\
\text { Not at all widespread }\end{array}$ & $\begin{array}{l}16 \\
12\end{array}$ & $\begin{array}{l}57.1 \\
42.9\end{array}$ \\
\hline $\begin{array}{l}\text { Change teaching style to avoid negative online ratings } \\
\text { Very likely } \\
\text { Likely/Somewhat likely } \\
\text { Not at all likely }\end{array}$ & $\begin{array}{l}1 \\
10 \\
17\end{array}$ & $\begin{array}{l}3.6 \\
35.7 \\
60.7\end{array}$ \\
\hline $\begin{array}{l}\text { Satisfied with the way institution handles faculty cyberbullying } \\
\text { Somewhat satisfied } \\
\text { Neither satisfied nor dissatisfied } \\
\text { Somewhat dissatisfied/Very dissatisfied }\end{array}$ & $\begin{array}{l}2 \\
19 \\
7\end{array}$ & $\begin{array}{l}7.1 \\
67.9 \\
25.0\end{array}$ \\
\hline $\begin{array}{l}\text { Faculty discussed expectations regarding students' responsible use } \\
\text { Internet, social media, and mobile technologies } \\
\text { No } \\
\text { Yes } \\
\text { Sometimes, but not always }\end{array}$ & $\begin{array}{l}5 \\
18 \\
5\end{array}$ & $\begin{array}{l}17.9 \\
64.2 \\
17.9\end{array}$ \\
\hline
\end{tabular}

Study participants were asked to indicate how they believed their career was affected by student ratings on ARS. One faculty member wrote that he/she noticed that his/her class enrollments had declined. The participant remarked, "a few weeks into the semester, one student told me that she was only in the class because she registered late and did not want to be in it because of Ratemyprofessors.com rating." Another participant wrote that "I believe students reading demeaning comments would not sign up for my class or believe I am too demanding as an instructor." A third faculty member indicated that ARS undermined his/her ability to do his/her job and be evaluated fairly. Another faculty member revealed that a colleague thought ARS websites were accurate. 
In contrast, a different faculty member indicated that a few disgruntled students who may have been reprimanded for plagiarism or were not happy with the workload used ARS to discredit instructors. The instructor believed that some of his/her new students did not like him/her from the start of class and he/she felt it could be due to ratings on ARS.

The current study revealed $4(14.3 \%)$ respondents who indicated they had been cyberbullied based on their faculty roles. They were provided a list of emotional and physical responses from which to choose and were asked to select all that apply based on their experiences. The list of potential effects was not exhaustive, and respondents could also enter responses not included in the list provided. The 4 faculty who reported being cyberbullied indicated they experienced anxiety and stress, $3(10.7 \%)$ also experienced fear, $2(7.1 \%)$ reported being angry and $2(7.1 \%)$ had become withdrawn. Other negative effects experienced by these faculty included difficulty concentrating, sleeping, feeling isolated, experiencing depression, and having emotional outbursts.

Respondents were asked if they discussed with their students their expectations regarding responsible use of the Internet, social media, and mobile technologies. The majority of respondents $(\mathrm{n}=18,64.2 \%)$ indicated they had discussed these expectations with students, while 5 (17.9\%) indicated they had not, and another $5(17.9 \%)$ indicated they had discussed their expectations sometimes, but not always.

Study respondents were offered an opportunity to provide open-ended feedback regarding ARS used to rate faculty and their responses included the following statements:

- So many in the university, faculty, administrators etc., do not have the time to get to know each other and instead rely on these [anonymous] sites as a shortcut. It is more difficult to build a reputation than in the past.

- I find it disturbing that the performance of professors is available for anyone to comment on in a public forum. Even non-students can post comments just to make someone look bad. I do not understand why this isn't regulated in some way. How many other people have jobs where they can be publicly criticized online for all to see? Not many. It adds a layer of stress to an already stressful job. It is especially distressing for those who are not tenured or do not have job security.

- How can we as faculty refute false claims on ratemyprofessor.com and other sites? These sites are harmful, concerning, and unfair to faculty who work hard to educate students with integrity and expertise.

- We had a student post negative comments on our School Facebook page about a class in another department. The Dean's office removed the comment and contacted the student directly to inform them that while the concern may be valid, the way to communicate it was not appropriate.

\section{Discussion}

The current study was a pilot with a small sample $(n=28)$ that could be used to explain mixed findings related to faculty cyberbullying on ARS. Blizard (2016) conducted a similar online survey focused on cyberbullying of college faculty with a small sample $(n=36)$. She explained that faculty may be hesitant to complete surveys related to cyberbullying because faculty may fear retaliation and be reminded of hurtful experiences. The current study relied on social media and a faculty listserv to recruit participants. This study investigated the extent to which faculty believed cyberbullying of college faculty was a problem on ARS, and if faculty discussed expectations regarding responsible use of ICTs with their students. ARS have been used by students to provide critical feedback related to their experiences with faculty. These sites have gained reputations for allowing sometimes harsh and unsubstantiated criticisms of faculty.

Cassidy et al. (2014) noted that the campus environment was not a safe, nurturing place for faculty who were cyberbullied by their students and others. Findings from the current study supported this contention, revealing that some faculty viewed student cyberbullying of faculty as a widespread concern on campus.

Most respondents in the current survey indicated that they had visited ARS to view their rankings and/or those of other faculty. Some respondents reported using anonymous online posts to make judgments about their faculty colleagues, with others viewing ARS as potentially harmful. Many respondents indicated comments posted about them on ARS were accurate.

Though some respondents in the current study did not agree with critiques about them on ARS, they were unlikely to change their teaching styles to avoid being cyberbullied. Cassidy et al. (2014) found that faculty in their study indicated cyberbullying had "affected their ability to work, their mental health, and their relationships outside the university" (p. 294). 
Respondents in the current study indicated they had experienced anxiety, stress, fear, and anger based on being cyberbullied. Other negative effects included depression, trouble concentrating, sleeping, and emotional outbursts. Faculty who experienced online abuse often continued teaching as they coped with the stress and anxiety resulting from cyberbullying (Blizard, 2016). As part of new faculty orientation, college administrators could provide faculty with cyberbully prevention education to inform faculty how to safeguard their reputations online, address negative posts, and report incidents of cyberbullying (Eskey, Taylor, \& Eskey, 2014).

Minor et al. (2013) surveyed 68 college faculty regarding cyberbullying of faculty. Minor et al. indicated that faculty worried that they would not receive support from supervisors, experienced embarrassment resulting from being cyberbullied, and feared job loss based on poor evaluations. Findings from the current study offered results that were consistent with research by Blizard (2016); Cassidy et al. (2014); and Minor et al. (2013). Although cyberbullying of college faculty exists, results indicated that cyberbullying of college faculty on ARS was not widespread.

Most respondents discussed expectations related to responsible use of ICTs with their students. This action could explain why few faculties reported being cyberbullying in the current study or did not feel it was problematic.

\subsection{ARS Abuse is not Widespread}

Although available research indicated cyberbullying of college faculty is not widespread, 19 (67.9\%) participants in the current study expressed varying levels of concern with being targeted for online abuse. Previous research (Cassidy et al., 2017; Blizard, 2015; Reid, 2010) focusing on cyberbullying of college faculty suggested that female faculty may be at greater risk for online abuse than their male counterparts.

Faculty who were concerned about being targeted on ARS could potentially reduce their risk potential for unfavorable online posts by educating their students about responsible online behavior (Fang, Mishna, Zhang, \& Van Wert, 2014). This education can be achieved by taking time during the first-class meeting to review the institution's social media policy, institutional technology use policy, and/or other institutional document(s) that provide guidance for students related to their use of ICTs. Understanding these policies could help students develop an entry-level framework for responsible online engagement without stifling their freedom of expression. Additionally, faculty could create a social media and/or technology use policy statement specific to their courses.

Faculty who are interested in counteracting unfavorable ARS posts could receive information on how to address potentially harmful online content. These faculty could write a formal letter to the offending site and request removal of specific content. Rombach (2003) indicated that letter writing was both therapeutic and action oriented. Faculty should reflect on their thoughts carefully, when writing a letter to communicate personal and professional effects of anonymous posts. Faculty can mail their letters to website administrator(s) where the offending content appears. While offending content might not be removed from ARS, this action can help reestablish feelings of personal control, self-empowerment, and emotional recovery.

Faculty who encounter cyberbullying on ARS could be counseled to abstain from visiting sites where emotionally charged, hurtful content has been identified. Faculty could be referred to professional consultants who specialize in reputational management services designed to assist individuals impacted by online posts. Reputational management specialists are skilled in removing undesirable online content and helping individuals and organizations repair their digital reputations (Woodruff, 2014). Online character repair services include companies like reputation.com, metalrabbitmedia.com, internetreputation.com, bigbluerobot.com, bulletproofdigital.com, and internet reputation services. Faucher et al (2015) argued that developing policies alone aimed at addressing cyberbullying will not alleviate the issue. Instead, policies must be implemented in such a way that targets of cyberbullies and the cyberbullies themselves are made aware of existing policies. Additionally, institutions should include strategies designed to raise awareness of support services that are available to those adversely impacted by cyberbullying. College and university cyberbullying prevention policies should include a process for evaluating the policy to determine if it is meeting its intended purpose and goals. Faculty, students, and staff should be encouraged to provide critical feedback related to the policy prior to final implementation. Soliciting faculty feedback could be especially helpful to developing and implementing a successful policy.

Based on the current study, most faculty indicated they had discussed expectations regarding the responsible use of the Internet, social media, and mobile technologies with their students. Research by Karpman and Drisko (2016) supported the practice of faculty educating their students about the responsible use of ICTs. 
These authors argued that students who violated social media use policies could place their colleges and universities in legal jeopardy due to their lack of awareness. Furthermore, "departments and universities as a whole lose out from not addressing bullying and cyberbullying behaviors adequately" (Cassidy et al., 2017, p. 15.). Having faculty encourage students to engage others respectfully online could have several positive outcomes. These outcomes could include helping students appreciate the effect their online behaviors could have on others, reducing potential barriers to students' post-degree employment based on their social media use, and safeguarding faculty reputations. Educating students about the effects of cyberbullying could also serve as a deterrent. For example, the majority of respondents in the current study reported discussing their expectations regarding responsible online behavior with their students. This action could help explain why so few respondents reported having experienced cyber bullying at the hands of their students.

\subsection{Limitations}

Generalizability of data from the current study may be limited as survey respondents were nearly homogeneous in terms of gender and ethnicity. This study used an online survey that was completed by 28 participants from multiple colleges and universities. The study did not explore if tenure-track faculty tended to experience cyber bullying more than tenured faculty or if female faculty were more susceptible to poor ARS scores and ratings than male faculty. Due to the small sample size, data analyses were limited to frequency distributions.

\subsection{Conclusion}

Based on available research, cyberbullying of college faculty is not a myth. While cyberbullying of college faculty is not widespread, it is a concern for some college faculty. Replicating the study with a larger sample with greater diversity could allow comparisons across different groups (tenured/non tenured, male/female, undergraduate/graduate). These comparisons could provide insight into the type of student who might target faculty and determine the extent to which cyberbullying focused on a particular type of professor. Additional research is needed to explore the perceptions of faculty cyberbullying of other faculty on ARS. Based on the current study, most participants had visited anonymous rating sites, with the majority indicating they believed the myth that faculty were being cyberbullied by students and other faculty. In addition, future research is needed to explore potential benefits that faculty and their institutions could enjoy from positive comments and strong scores posted on ARS about these faculty.

\section{References}

Bandura, A. (1977). Social learning theory. Englewood Cliffs, N.J: Prentice Hall.

Bauman, S., \& Bellmore, A. (2015). New Directions in Cyberbullying Research. Journal of School Violence, 4(1), 1-10. doi.org/10.1080/15388220.2014.968281

Bleske-Rechek, A. \& Fritsch, A. (2011). Student consensus on RateMyProfessors.com. Practical Assessment, Research \& Evaluation, 16(18). Retrieved from https//pareonline.net/getvn.asp? $\mathrm{v}=16 \& \mathrm{n}=18$

Bleske-Rechek, A. \& Michels, K. (2010). RateMyProfessors.com: Testing assumptions about student use and misuse. Practical Assessment, Research \& Evaluation, 15(5). Retrieved from https//pareonline.net/getvn.asp?v=15\&n $=5$

Blizard, L. (2016). Faculty members' experiences of cyberbullying by students at one Canadian university: Impact and recommendations. International Research in Higher Education. 1(1), 107-124. doi: 10.5430/irhe.v1n1p107

Brown, C. L., \& Kosovich, S. M. (2015). The Impact of Professor Reputation and Section Attributes on Student Course Selection. Research in Higher Education, 56(5), 496-509.doi.org/10.1007/s11162-014-9356-5

Cassidy, W., Faucher, C., \& Jackson, M. (2014). The dark side of the ivory tower: Cyberbullying of university faculty and teaching personnel. Alberta Journal of Educational Research, 60(2), 279-299. Retrieved from https://journalhosting.ucalgary.ca/index.php/ajer/index

Cassidy, W.,Faucher, C., \& Jackson, M. (2017). Adversity in university: Cyberbullying and its impacts on students, faculty and administrators. International Journal of Environmental Research and Public Health, 14, 888-906. doi:10.3390/ijerph14080888

Daniloff, C. (2009, April 22). Cyber bullying goes to college: Online harassment can turn campus life into a virtual hell. BU Today. Retrieved from http://www.bu.edu/today/2009/cyberbullying-goes-to-college/ 
Eskey, M. T. \& Roehrich, H (2015). Cyberbullying in the online classroom: Planning, training, and policies to protect online instructors. Journal of Social Sciences and Humanities, 1(2), 67-74. Retrieved from files.aiscience.org/journal/article/pdf/70320014.pdf

Eskey, M. T., Taylor, C. L., \& Eskey Jr, M. T. (2014). Cyber-Bullying in the Online Classroom: Instructor Perceptions of Aggressive Student Behavior. Online Journal of Distance Learning Administration, 17(4). Retrieved fromhttps://www.learntechlib.org/p/168157/.

Fang, L., Mishna, F, Zhang, V. \& Van Wert, M. (2014). Social media and social work: Understanding and dealing with the new digital world. Social Work in Health Care, 53(9), 800-814, doi: 10.1080/00981389.2014.943455

Faucher, C., Jackson, M., \& Cassidy, W. (2015). When on-line exchanges byte: An examination of the policy environment governing cyberbullying at the university level. Canadian Journal of Higher Education, 45(1), 102-121.Retrieved from http://journals.sfu.ca/cjhe/index.php/cjhe/article/view/184215/pdf_3

Hayes, M. W., \& Prus, J. (2014). Student use of quantitative and qualitative information on Ratemyprofessors.com for course selection. College Student Journal, 48(4). 675-688. Retrieved from https://www.ingentaconnect.com/content/prin/csj/2014/00000048/ 00000004/art00012

Hill, J. R., Song, L., \& West, R. E., (2009). Social learning theory and web-based learning environments: A review of research and discussion of implications, The American Journal of Distance Education, 23:2, 88-103, doi: 10.1080/08923640902857713

Hossain, T. M. (2010). Hot or not: An analysis of online professor-shopping behavior of business students. Journal of Education for Business, 85(3), 165-171. doi: 10.1080/08832320903252439

Karpman, H. \& Drisko, J. (2016). Social media policy in social work education: A review and recommendations. Journal of Social Work Education, 52(4), 398-408. doi.org/10.1080/10437797.2016.1202164

Kolowich, S. \& Quintana, C. (2017, December 21). A Brief History of Students Secretly Recording Their Professors. Chronicle of Higher Education. Retrieved from https://www.chronicle.com/article/A-BriefHistory-of-Students/242104

Kornell, N., \& Hausman, H. (2016). Do the best teachers get the best ratings? Frontiers in Psychology. 7(570). doi:10.3389/fpsyg.2016.00570

Miranda, M.V. (2018). Turning the Tables: Using RateMyProfessors.com as a Teaching Tool in the Community College Classroom. College Student Journal, 52(1), 74-80. Retrieved from https://www. ingentaconnect.com/contentone/prin/csj /2018/00000052/ 00000001/art00007

Miller, B., \& Morris, R. G. (2016). Virtual peer effects in social learning theory. Crime \& Delinquency, 62(12), 1543-1569. doi: 10.1177/0011128714526499

Minor, M., Smith, G. \& Brashen, H. (2013). Cyberbullying in higher education. Journal of Educational Research and Practice, 3(1), 15-29. doi: 10.5590/JERAP.2013.03.1.02

Otto. J., Sanford, Jr., D. \& Ross, D. (2008) Does ratemyprofessor.com really rate my professor? Assessment \& Evaluation in Higher Education, 33(4), 355-368. doi: 10.1080/02602930701293405

Perna, G. (2016). Own your online reputation before someone else does. Medical Economics, 93(4), 74-77. Retrieved from https://europepmc.org/abstract/med/27079079

Reid, L. (2010). The role of perceived race and gender in the evaluation of college teaching on RateMyProfessors.com. Journal of Diversity in Higher Education, 3(3), 137-152. doi: 10.1037/a0019865

Roblyer, M.D., McDaniel, M., Webb, M., Herman, J., \& Witty, J. V. (2010). Findings on Facebook in higher education: A comparison of college faculty and student uses and perceptions of social networking sites. The Internet and Higher Education, 13(3), 134-140. doi.org/10.1016/j.iheduc.2010.03.002

Rombach, M. (2003). An invitation to therapeutic letter writing. Journal of Systemic Therapies, 22(1), 15-32. doi: 10.1521/jsyt.22.1.15.24097

Watts, L. K., Wagner, J., Velasquez, B., \& Behrens, P. I. (2017). Cyberbullying in higher education: A literature review. Computers in Human Behavior, 69,268-274. doi:10.1016/j.chb.2016.12.038.

Woodruff, A. (2014, April). Necessary, unpleasant, and disempowering: reputation management in the internet age. In Proceedings of the SIGCHI conference on human factors in computing systems (pp. 149-158). ACM. doi: 10.1145/2556288.2557126

Zalaquett, C. \& Chatters, S. (2014). Cyberbullying in college: Frequency, characteristics, and practical implications. SAGE Open, 4, 1-8. doi: 10.1177/2158244014526721 